\title{
Wear assessment of tin and tin alloy coatings
}

\author{
W. P.-W. Lam ${ }^{1}$, K. $\mathrm{Mao}^{2}$, C. Kerr ${ }^{1} \&$ T. A. Stolarski ${ }^{2}$ \\ ${ }^{1}$ ITRI Ltd., UK \\ ${ }^{2}$ Department of Mechanical Engineering, Brunel University, UK
}

\begin{abstract}
Tin and tin alloys have traditionally been used as coating materials for a variety of functions, e.g. decorative, solderable and corrosion resistant, but rarely in applications that require physical durability, owing to the soft nature of tin. Although it has been reported that some alloys of tin are comparatively harder, these materials have traditionally been used as corrosion resistant coatings and there has been little research conducted on exploring their physical properties. This paper aims to demonstrate the range of durability augmentation achieved from alloying tin with copper and nickel in coatings electrodeposited onto steel by assessing the degree of coating removal caused by wear from a sliding ceramic ball contact on the coating surface. The degree of wear is measured by the level of iron detected (i.e., where coating removal has resulted in the exposure of the underlying steel), via EDX, and this is correlated with 1) different loads $(10-50 \mathrm{~N}$ at ten Newton increments) at which the ceramic ball is applied; 2) the thickness of the tin/tin alloy deposits (2, $5 \& 10$ microns) and 3) the wear testing duration $(1-8$ hours at one hour increments). The results are then presented in the form of a matrix. The study confirmed that tin performed poorly, and revealed significant improvements when tin is alloyed with nickel or copper.
\end{abstract}

Keywords: sliding wear, coating, SEM/EDX, tin, tin-nickel, tin-copper.

\section{Introduction}

This paper assesses the possibility of using tin and tin alloy coatings in an application not previously considered before. The suitability of the materials in question is evaluated using a novel method, where the degree of coating removal is quantified. Concluding comments and suggestions for further work are presented at the end of the paper. 


\subsection{General applications of tin and tin alloy coatings}

Uses of tin and tin alloys in packaging and electronics industry comprise around $60 \%$ of the tin usage market [1-3]. Other uses include decorative or corrosion resistant coatings [4].

Tin and tin alloys, however, have not traditionally been considered as wear resistant coating materials, owing to its physical properties. When compared with other materials, metals and alloys, tin is a soft and malleable metal [1] that is often dismissed as a candidate material for wear applications that have traditionally required hard and robust properties [5].

Previous research has already reported on the corrosion resistant properties of tin-copper and tin-nickel alloys [6-7], and the intention is to assess these two alloys, with tin, in a sliding wear environment. A coating with a dual resistance to both corrosion and wear would have clear implications for industry.

\subsection{Selecting the technique for assessing wear resistance}

Although coatings can be assessed in a number of ways, including pull-off tests for adhesion and four-point bend tests for inducing coating delamination [5], it was decided that the testing in this research should introduce a form of deformation of the coating material that is representative of in-service wear.

The most common technique for assessing wear resistance is by measuring the coefficient of friction or by weight loss of the material [8], however, both of these methods have not been considered for the following reasons:

- The effectiveness of soft coatings is due to the solid lubrication properties they offer via reduction of friction. Measuring of this reduction in friction coefficient may provide some indication of when the coating has been breached, but it does not give any quantitative indication of the degree of coating depletion.

- The weight loss incurred by the coatings in this research are negligible and initial trials using a thick coating, large load and long test duration have indicated that there was insufficient material loss for detection.

A coating that offers protection to the underlying substrate is only performing its role while it is still adhered. It is therefore decided that the retention of the coating is to be assessed in this research and the continual monitoring of the removal of the coating is carried out by inspection of the wear scar surface. The use of a surface sensitive analytical technique, namely EDX, is considered for the examination of elemental composition in the wear scar location, enabling the ratio between detected coating and substrate material to be evaluated.

\subsection{Coating deposition and characterisation}

\subsubsection{Electrodeposition}

Using a combination of Hull Cell testing and available electroplating literature [4, 9-12], coatings of tin, tin-nickel and tin-copper were deposited on steel substrates measuring $40 \times 22 \mathrm{~mm}^{2}$. 


\subsubsection{Characterisation}

The electrodeposits were characterised on several counts:

- The electroplated tin and tin alloy deposits were examined using a Topcon SM300 Scanning Electron Microscope (SEM) to show that, in all cases, a uniform coating and complete coverage was deposited.

- Using an Oxford Instruments INCA Energy Dispersive X-ray (EDX) system, it was possible to determine that the elemental compositions of deposits have been electroplated. It is also important to confirm the absence of iron from the surfaces looked at, indicating that the underlying steel substrates have been completely obscured.

- Using conventional metallographic preparation techniques, the deposits were microsectioned in order to determine their thicknesses with respect to the plating duration. In this way, it was possible to ascertain the exact plating times for producing 2,5 and 10 micron coatings for the three deposits.

\section{Methodology}

The wear assessment is conducted on the tin, tin-nickel and tin-copper coated coupons. This Section presents the method for determining wear resistance, which has been divided into two parts.

\subsection{Wear testing}

The wear coupons, which have been coated with three different finishes, each at three different thicknesses, are tested using a TE70 micro-friction machine. This setup involves the sliding contact of a hard ceramic ball over the surface of the wear specimen (Figure 1).

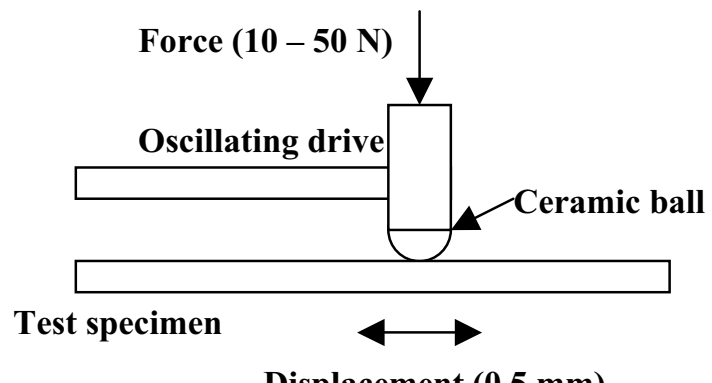

Displacement (0.5 mm)

Figure 1: $\quad$ Schematic of TE70 machine setup used for wear testing. 
The TE70 default settings of frequency $(10 \mathrm{~Hz})$ and displacement $(0.5 \mathrm{~mm})$ are maintained. These determine, respectively, the speed at which the ball slides and the distance of the sliding action.

An adjustable load carrier directly over the ceramic ball enables the test to be carried out under different loads. The load carrier applies a force of $10 \mathrm{~N}$, whilst its capacity allows up to four $10 \mathrm{~N}$ weights to be added for a maximum total of $50 \mathrm{~N}$. In this study, wear testing was conducted at 10, 20, 30, 40 and $50 \mathrm{~N}$ to investigate the effect of an increasing load.

The wear testing was carried out at 1, 2, 3, 4, 5, 6, 7, and 8 hour durations to investigate the effect of an increasing wear time.

\subsection{Wear scar assessment}

The resulting wear scars are examined using SEM and EDX in order to determine the extent of damage introduced by contact with the sliding ceramic ball. This is achieved by measuring the amount of detectable Fe within the wear scar. The amount of Fe detected for 0 hour samples is negligible; therefore, any Fe detected within the wear scar will be from the underlying steel substrate, which has been exposed by removal of the coating.

EDX is used to evaluate the approximate level of exposed Fe by acquiring from a rectangular area within the wear scar. Figure 2 illustrates the rectangle drawn within the wear scar, designating the area where the EDX acquisition is to take place.

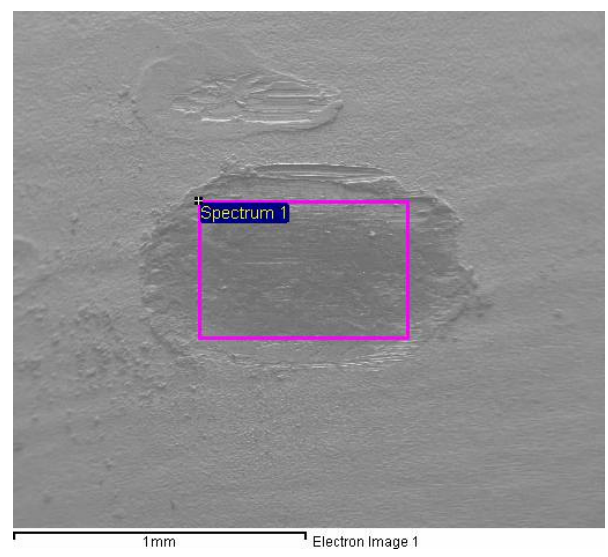

Figure 2: Area within wear scar selected for EDX analysis.

The Fe content detected is presented as a weight percentage, and recorded with reference to the coating material, coating thickness, load used and the duration of the wear test.

For the benefit of presentation and data analysis, the degree of coating removal has been separated and graded into five different categories: 
- Negligible: 0 - $20 \mathrm{wt} \%$ Fe detected

- Moderate: 20 - $40 \mathrm{wt} \%$ Fe detected

- Significant: $40-60 \mathrm{wt} \%$ Fe detected

- Critical: $60-80 \mathrm{wt} \% \mathrm{Fe}$ detected

- Failure: $80-100 \mathrm{wt} \%$ Fe detected

The results are presented, for each coating, in the form of a matrix, where an individual cell corresponds to a certain set of test parameters. The cells are shaded with respect the degree of coating removal, with a darker shade denoting more iron detected, the key to which is presented by Table 1 .

Table 1: Legend defining shading used in Results Matrices for each condition/range of wt $\% \mathrm{Fe}$ detected.

\begin{tabular}{|l|l|l|l||r|}
\hline Negligible & Moderate & Significant & Critical & Failure \\
\cline { 1 - 4 } $0-20$ & $20-40$ & $40-60$ & $60-80$ & $80-100$ \\
\hline
\end{tabular}

\section{Results}

The results matrix is presented for the coatings tested (Table 2), and is shaded according to the amount of exposed Fe detected.

\subsection{Tin coating}

Examination of the wear scars showed that there was a negligible degree of tin coating removed $(0-20 \mathrm{wt} \% \mathrm{Fe}$ detected) from the conditions tested. Even the testing of the thickest coating (10 micron) with the minimum load $(10 \mathrm{~N})$ within the minimum test duration ( 1 hour) yielded a moderate amount of tin removal $(20-40 \mathrm{wt} \% \mathrm{Fe}$ detected).

Testing on the tin coating was conducted up to $30 \mathrm{~N}$, due to the amount of coating removed at the weight. Further increases in load would have yielded little further information.

\subsection{Tin-nickel coating}

The tin-nickel deposit was investigated with loads from 10 to $50 \mathrm{~N}$. Although the thinnest coating ( 2 microns) had been fully removed after just 2 hours at $30 \mathrm{~N}$, $50 \mathrm{~N}$ was necessary to ensure full removal of the 5 and 10 micron coatings.

\subsection{Tin-copper coating}

Testing of the tin-copper deposit was also conducted using the full $10-50 \mathrm{~N}$ load range. $10 \mathrm{~N}$ yielded negligible steel substrate exposure, even when testing for 8 hours on the thinnest coating thickness ( 2 microns). Using the maximum load of $50 \mathrm{~N}$ was sufficient to remove all coating from the 2 and 5 micron deposits, but not from the 10 micron samples. 
Table 2: Results matrix for testing conducted on tin, tin-nickel and tincopper coatings.

\begin{tabular}{|c|c|c|c|c|c|c|c|c|c|c|}
\hline \multirow{2}{*}{$\begin{array}{l}\text { Testing } \\
\text { Force / } \\
\mathbf{N} \\
\end{array}$} & \multirow[b]{2}{*}{$\begin{array}{c}\text { Testing } \\
\text { duration } \\
/ \text { hrs }\end{array}$} & \multicolumn{3}{|c|}{ Tin } & \multicolumn{3}{|c|}{ Tin-Nickel } & \multicolumn{3}{|c|}{ Tin-Copper } \\
\hline & & $\begin{array}{l}2 \\
\mu \mathrm{m}\end{array}$ & $\begin{array}{l}5 \\
\mu \mathbf{m}\end{array}$ & $\begin{array}{l}10 \\
\mu \mathrm{m}\end{array}$ & $\begin{array}{l}2 \\
\mu \mathrm{m}\end{array}$ & $\begin{array}{l}\mathbf{5} \\
\mu \mathbf{m}\end{array}$ & $\begin{array}{l}10 \\
\mu \mathrm{m}\end{array}$ & $\begin{array}{l}2 \\
\mu \mathbf{m}\end{array}$ & $5 \mu \mathrm{m}$ & $\begin{array}{l}10 \\
\mu \mathrm{m}\end{array}$ \\
\hline \multirow{8}{*}{10} & 1 & & & & & & & & & \\
\hline & 2 & & & & & & & & & \\
\hline & 3 & & & & & & & & & \\
\hline & 4 & & & & & & & & & \\
\hline & 5 & & & & & & & & & \\
\hline & 6 & & & & & & & & & \\
\hline & 7 & & & & & & & & & \\
\hline & 8 & & & & & & & & & \\
\hline \multirow{8}{*}{20} & 1 & & & & & & & & & \\
\hline & 2 & & & & & & & & & \\
\hline & 3 & & & & & & & & & \\
\hline & 4 & & & & & & & & & \\
\hline & 5 & & & & & & & & & \\
\hline & 6 & & & & & & & & & \\
\hline & 7 & & & & & & & & & \\
\hline & 8 & & & & & & & & & \\
\hline \multirow{8}{*}{30} & 1 & & & & & & & & & \\
\hline & 2 & & & & & & & & & \\
\hline & 3 & & & & & & & & & \\
\hline & 4 & & & & & & & & & \\
\hline & 5 & & & & & & & & & \\
\hline & 6 & & & & & & & & & \\
\hline & 7 & & & & & & & & & \\
\hline & 8 & & & & & & & & & \\
\hline \multirow{8}{*}{40} & 1 & & & & & & & & & \\
\hline & 2 & & & & & & & & & \\
\hline & 3 & & & & & & & & & \\
\hline & 4 & & & & & & & & & \\
\hline & 5 & & & & & & & & & \\
\hline & 6 & & & & & & & & & \\
\hline & 7 & & & & & & & & & \\
\hline & 8 & & & & & & & & & \\
\hline \multirow{8}{*}{50} & 1 & & & & & & & & & \\
\hline & 2 & & & & & & & & & \\
\hline & 3 & & & & & & & & & \\
\hline & 4 & & & & & & & & & \\
\hline & 5 & & & & & & & & & \\
\hline & 6 & & & & & & & & & \\
\hline & 7 & & & & & & & & & \\
\hline & 8 & & & & & & & & & \\
\hline
\end{tabular}




\section{Discussion}

Both tin-nickel and tin-copper significantly out-perform tin, as expected, with the alloy coatings being retained for a far longer test duration and resistant to far greater loads.

\subsection{Tin-nickel coating}

Increasing the tin-nickel coating thickness significantly prolongs the retention of the coating and retards the exposure of the underlying steel substrate by a greater margin than the same increase has for a tin coating.

At $10 \mathrm{~N}$, the level of exposed steel after testing for 6 hours on a 2 micron deposit is nearly $90 \%$, decreasing to $\sim 40 \%$ with a 5 micron deposit and further falling to $\sim 0 \%$ for a 10 micron deposit. This large improvement is also reflected for tests using 20,30 and $40 \mathrm{~N}$.

The increasing of the load from 10 to $20 \mathrm{~N}$ initiates the trend at an earlier stage. At 4 hours, testing with $20 \mathrm{~N}$, the 2 micron coating had failed, whilst the 5 micron coating was at a critical condition, however, there was negligible damage detected for the 10 micron coating.

At $30 \mathrm{~N}$, the 2 micron coating fails after 2 hours. Under the same load and within the same duration, the 5 micron coating is significantly removed whilst there is negligible Iron found at the surface of the 10 micron coating. The 10 micron coating shows no sign of any removal for testing at 8 hours with loads of up to $30 \mathrm{~N}$.

The 2 micron coating fails after one hour of testing with $40 \mathrm{~N}$, whilst the 5 micron coating suffers critical damage. The $40 \mathrm{~N}$ load, however, is not sufficient to cause any notable damage to the 10 micron coating until 7 hours, when moderate coating removal is detected. Even after 8 hours testing, the 10 micron coating only yields $\sim 50 \mathrm{wt} \%$ iron at the wear scar.

At $50 \mathrm{~N}$, the load appeared to be sufficient, after just 1 hour, to cause a critical condition $(60-80 \mathrm{wt} \% \mathrm{Fe})$ for both the 5 and 10 micron coatings, with failure occurring after 2 hours of testing.

A 5 micron coating of tin-nickel, when tested using a $30 \mathrm{~N}$ load, performs comparably with a 2 micron coating of tin-nickel tested at $20 \mathrm{~N}$. In both cases, testing for 1 hour yields a moderate degree of coating removal and a second hour of testing results in a significant case of steel exposure. At 3 hours, the coating removal becomes critical and the coating is considered to have failed after 4 hours.

A 10 micron coating of tin-nickel, when tested using a $50 \mathrm{~N}$ load, performs comparably with a 2 micron coating of tin-nickel tested at $30 \mathrm{~N}$. In both cases, testing for 1 hour yields a high level of coating removal and, after a second hour of testing, the coating fails.

\subsection{Tin-copper coating}

The increase in tin-copper thickness from 2 to 5 microns does not appear to significantly prolong the retention of the coating. This is characterised by the 
proximity of the two sets of results, particularly at high loads. This is not so apparent at $10 \mathrm{~N}$, where, after 8 hours of testing, less than $40 \mathrm{wt} \% \mathrm{Fe}$ is detected and negligible damage is introduced to the 5 and 10 micron deposits.

At loads of $20 \mathrm{~N}$ and above, the increase from 5 to 10 microns, however, appears to yield a marked increase in performance of the coating at retarding the exposure of the underlying steel substrate.

After increasing the load to $20 \mathrm{~N}$, failure of the thinnest coating is first observed after 7 hours of testing. At this point, the 5 micron coating is in a critical state, however, there is still negligible damage to the 10 micron deposit. There is no significant increase in Fe detection after 8 hours.

With a load of $30 \mathrm{~N}$, failure of both the 2 and 5 micron coatings were discovered after 3 hours, whilst the 10 micron coating had still yet to experience any notable damage. This is similar to observations made at $20 \mathrm{~N}$ for the $\mathrm{SnNi}$ coating, where a similar set of results were obtained after 4 hours.

One hour of testing using $40 \mathrm{~N}$ appears to be sufficient to nearly completely remove the 2 micron coating. At this stage, the 5 micron coating exhibits some degree of removal, whilst the 10 micron coating is showing no evidence of being breached.

A second hour of testing yields significant further damage in the 5 micron coating, which ultimately fails after 3 hours testing. The 10 micron coating, however, is gradually depleted but falls short of the critical status when testing concludes at 8 hours.

At $50 \mathrm{~N}$, the 2 and 5 micron coatings behave very similarly, failing at 1 and 3 hours respectively. The 10 micron coating reaches a critical condition after 6 hours, and maintains this status for the remainder of the 8 hour test.

At low loads, the 2 micron $\mathrm{SnCu}$ coating appears to out-perform the 5 micron SnNi deposit.

\subsection{Summary}

The pure tin coating performs relatively poorly, as expected, owing to its comparatively soft and malleable nature, and it is possible that the metal is so soft that the even the solid lubricating properties are nullified. Testing with the lowest load, $10 \mathrm{~N}$, was sufficient to cause complete coating removal in both the 2 and 5 micron deposits (after 4 and 5 hours, respectively), and critical damage to the 10 micron coating (after the maximum 8 hour test duration). Increasing the load to $20 \mathrm{~N}$ caused complete failure of the 10 micron coating (after 3 hours).

Coatings of tin-nickel performed significantly better and testing with $10 \mathrm{~N}$ resulted in failure of only the 2 micron coating (after 6 hours). Testing with $20 \mathrm{~N}$ yielded failure in the 5 micron coating (after 5 hours), whilst the 10 micron coating was able to endure testing with loads of up to $40 \mathrm{~N}$ without critical damage. The 10 micron coating was eventually removed after 2 hours of testing with a maximum load of $50 \mathrm{~N}$.

The tin-copper coatings were also a significant improvement on the tin metal deposits, in most case, even surpassing the performances of the tin-nickel alloy. $10 \mathrm{~N}$ appeared to be insufficient for generating failure in any of the tin-copper deposits, with failure of the 2 micron coating first achieved with $20 \mathrm{~N}$ (after 7 
hours). Failure for the 5 micron thickness was observed at $30 \mathrm{~N}$ (after 3 hours), whilst the 10 micron coating was never fully removed, even after testing at the maximum $50 \mathrm{~N}$ load for the full 8 hour duration.

\section{Conclusions}

Three different deposits (tin, tin-copper and tin-nickel) of three set thicknesses (2, 5 and 10 microns) were successfully applied onto steel coupons. Using a combination of analytical techniques, it is possible to confirm deposition of complete coating coverage, and uniformity in composition and thickness. This is important for the generation of consistent results from the subsequent testing and analysis.

The wear resistant properties of the coatings produced are assessed using a novel methodology, where the degree of wear is quantitatively evaluated by analysis of the wear scar with SEM/EDX.

Although tin and tin alloys are not generally considered as candidate coating materials for wear resistant applications, but rather for decorative, corrosion resistant and solderable coatings, the alloying with copper and nickel greatly increases the wear characteristics of tin. For example, a $20 \mathrm{~N}$ force, that would yield a wear scar and remove nearly all the tin coating from the surface, could be applied to a similar thickness of tin-nickel or tin-copper for the same length of time, and result in little or no coating removal.

\section{Further work}

The effect of alloying other metals with tin is currently being considered, with intentions for tin-zinc, tin-cobalt and, possibly, tin-manganese to be investigated on in the near future.

Another avenue that is being looked into is the effect of incorporating particles, such as, PTFE and WC into the tin-alloy coatings, by process of codeposition, on the wear resistant property.

\section{References}

[1] Evans C.J., Tin Handbook, Huthig GmbH, 1994

[2] Klein-Wassink R.J., Soldering in Electronics, Electrochemical Publications, 1989

[3] Hwang J.S., Environment-Friendly Electronics: Lead-Free Technology, Electrochemical Publications, 2001

[4] Chapman A.H., Tin and Tin-Alloy Plating - A Review, ITRI Publication No. 606, 1980

[5] Mellor B.G., Surface Coatings for Protection against Wear, Woodhead Publishing, 2006

[6] Britton S.C., Tin Versus Corrosion, ITRO Publication No. 510, 1975 
[7] Warwick M.E., Hampshire W.B., Atmospheric Corrosion of Tin and Tin Alloys, John Wiley \& Sons, 1982

[8] Hutchings I.M., Tribology: Friction and Wear of Engineering Materials, 1992

[9] Cuthbertson J.W., The Hull Cell, Metal Industry, 1951, Vol. 79 No. 5, 87

[10] Parkinson N., Electrodeposition of Bright Tin-Nickel Alloy Plate, J. Electrodepositors' Tech. Soc., 1951, 27, 129

[11] Price J.W., Tin and Tin-Alloy Plating, Electrochemical Publications, 1983

[12] Baugh L.M., Processes and Applications for Tin and Tin-Based Alloy Surface Coating Technologies, A Technical Review and Assessment of Recent Developments Compiled for Tin Technology, 2005 